\title{
SEIS PASSEIOS PELO TEXTO POÉTICO
}

(Editorial)

\section{Antônio Donizeti PIRES ${ }^{1}$ \\ Solange Fiuza Cardoso YOKOZAWA ${ }^{2}$}

Publicam-se, neste volume 13 da revista TextoPoético (referente ao segundo semestre de 2012), vários trabalhos de membros do GT Teoria do Texto Poético, bem como de resenhistas convidados. Ligados a vários Programas de Pós-Graduação semeados por vários pontos do Brasil, os membros do GT aqui representados tiveram seus textos comunicados e debatidos, primeiramente, no XXVII ENANPOLL (Encontro Nacional da ANPOLL), o qual teve lugar na UFF, Niterói, RJ, entre os dias 10 e 13 de julho de 2012, sendo que o rol de resumos dos 22 trabalhos apresentados pode ser acessado e lido no site da ANPOLL: http://www.anpoll.org.br/eventos/enanpoll2012.

Para esta edição de TextoPoético contam-se 17 artigos, distribuídos de modo a evidenciar-se, no conjunto, um arco diacrônico que vai da modernidade à contemporaneidade; ou das origens dúbias da lírica moderna à experimentação mais atual da poesia com outras linguagens e novas tecnologias; ou da afirmação do poeta/sujeito moderno ao questionamento pós-moderno (pós-lírico, pós-utópico) do que sejam, hoje, os conceitos problemáticos de "subjetividade" e "poesia lírica", que se imbricam mútua e medularmente. Em suma, a diacronia escolhida não é aleatória, na medida em que seu estabelecimento (em temporalidades e espaços descontínuos) lança novas luzes sobre a reflexão sincrônica, atual, acerca da poesia e do discurso poético.

Assim, embora não se agrupem em sessões temáticas, é possível estabelecer-se um roteiro de leitura que comece, por exemplo, por três estudos sobre a literatura francesa do

1 Departamento de Literatura. Programa de Pós-Graduação em Estudos Literários. Faculdade de Ciências e Letras. Universidade Estadual Paulista (UNESP), campus de Araraquara, CEP 14800-901, Araraquara - SP Brasil - adpires@,fclar.unesp.br

2 Programa de Pós-Graduação em Letras e Linguística. Faculdade de Letras, Universidade Federal de Goiás (UFG), CEP 74001-970, Goiânia - GO - Brasil - solfiuza@hotmail.com 
século XIX acoplados a um estudo de poesia brasileira contemporânea: o primeiro é voltado para o nascente poema em prosa (tão caro aos atentos poetas contemporâneos) e as relações sonho e poesia (caso de "Sonho e poesia em Gaspard de la Nuit de Aloysius Bertrand", de Adalberto Luis Vicente - UNESP/Araraquara); o segundo, para a apreciação do motivo exótico na poesia de Charles Baudelaire (caso de "O convite à viagem: notas sobre o exótico nas Flores do mal", de Paulo Franchetti - UNICAMP); e o terceiro para as relações Romantismo-Realismo em certa "prosa menor" francesa de transição, bastante ligada à arte da gravura e atenta ao humor e às novas formas textuais jornalísticas (caso de "Estetização da escrita prosaica", de Celina Maria Moreira de Mello - UFRJ). Tais formas, se alteraram a produção e a recepção da literatura, no século XIX, também foram irrigadas por ela, numa evidência de que novas formas de comunicação de massa (o jornal, a internet, as novas tecnologias) estão sempre em interdiálogo com a literatura, a exemplo do que acontece hoje com parte significativa da poesia brasileira (caso do artigo "Poesia e técnica: perspectivas e diálogos da criação poética no contexto das artes e das tecnologias digitais”, de Rogério Barbosa da Silva - CEFET/MG).

Deste último artigo, o leitor pode saltar para alguns outros pontos de reflexão crítico-teórica sobre nossa poesia contemporânea, seja no instigante estudo de Solange Fiuza Cardoso Yokozawa (UFG), "Razões de um desconforto: notas a propósito de dois artigos sobre poesia brasileira contemporânea e tradição"; seja na sondagem dos mistérios da criação poética, indo do Íon platônico à contemporaneidade em “O processo de criação poética", de Norberto Perkoski (UNISC/RS); seja conferindo tais perspectivas sobre o poeta inspirado e o poeta artesão na bela entrevista "A poesia é o paraíso do paradoxo"”, a nós concedida pelo jovem poeta Rodrigo Petronio.

O leitor pode aproveitar a "deixa" e aninhar-se, digamos assim, em mais dois artigos que enfocam a relação poesia e pintura no trabalho atual de duas mulheres artistas não tão (ou quase nada) canônicas, estudadas respectivamente em "Campos de imagens literárias em Lília A. Pereira da Silva: poesia-desenho-pintura”, de Antonio Donizeti da Cruz (UNIOESTE/PR), e em “A forma óbvia: poesia e pintura em Lucinda Persona”, de Célia Maria Domingues da Rocha Reis \& Renato Cardoso de Moraes (UFMT).

Ou, se o leitor preferir expandir sua reflexão para a América Latina e quiser recordar a importância de um Oswald de Andrade para os poetas concretistas (lendo os dois artigos 
sob a batuta da antropofagia oswaldiana - e/ou sob os arcanos do neobarroco latinoamericano de um Lezama Lima e/ou de um Haroldo de Campos), aconselhamos que se fixe então em "Las eras imaginarias e La expresión americana: uma reinvenção imagética da América Latina”, de Ximena Antonia Díaz Merino (UNIOESTE/PR), e “O rosto da memória: Décio \& Oswald”, de Maria Aparecida Junqueira (PUC/SP).

Enfim, voltando o foco de seu interesse para a poesia brasileira, o leitor tem ainda um grupo interessante de estudos analítico-interpretativos de poetas, poemas e livros de poemas publicados entre o florescimento de nosso Modernismo e o momento presente, segundo revelam os títulos dos ensaios: "Noturnas águas melancólicas: sobre 'Noturno da Mosela', de Manuel Bandeira”, de Wilson José Flores Jr. (UFRJ); “As ocorrências do ‘eu’ na poesia de João Cabral”, de Éverton Barbosa Correia (UFPB); “A imaginação material e a poética das águas em João Cabral”, de Maria de Fátima Gonçalves Lima (PUC/GO); “Questões para uma antologia da poesia brasileira de 1964 a 1985”, de Cristiano Augusto da Silva Jutgla (UESC/BA); "O corpo fora, de Francisco Alvim, como contracena da mitologia da mineiridade", de Fernando Fiorese (UFJF); "No olhar oblíquo, a poesia", de Kelcilene Grácia-Rodrigues (UFMS/Três Lagoas), sobre a poesia de Manoel de Barros; e "Poesia, riso e testemunho em Umbigo (2006), de Nicolas Behr", de Wilberth Salgueiro (UFES).

A este último grupo de artigos ligam-se as seis resenhas (sobre livros de poesia lançados em 2010) ora publicadas neste volume da TextoPoético, na seguinte ordem: Leandro Durazzo (Universidade de Lisboa) e Kelcilene Grácia-Rodrigues (UFMS/Três Lagoas), em "O menino-poeta: no olhar oblíquo, a poesia", comentam em parceria Menino do mato (2010), de Manoel de Barros; Ilca Vieira de Oliveira (UNIMONTES/MG), em “As dimensões do universo poético de Linear G, de Gilberto Mendonça Teles”, apresenta o último livro (2010) do poeta-crítico; Fabiane Renata Borsato (UNESP/Araraquara), em "Mobilidade e fixidez de uma poesia em trânsito", resenha o último livro de Alberto Martins, Em trânsito (2010); Anelito Pereira de Oliveira (UNIMONTES/MG), em "O rosto da poesia", apresenta Palavra e rosto (2010), de Fernando Paixão; Alexandre Bonafim Felizardo (USP/UEG) comenta Roseiral (2010), de José Inácio Veira de Melo, em "Roseiral de vertiginosa poesia"; por seu turno, Leonardo Vicente Vivaldo 
(UNESP/Araraquara) estuda, em "A máquina do mundo (re)quebrada", os enfim Poemas reunidos (2010) do mineiro-carioca Geraldo Carneiro.

O leitor atento terá percebido que tal proposta ziguezagueante de leitura sincrônica não corresponde à ordem diacrônica dos textos no "Sumário" e no corpo da revista. Mas ela é eficaz na medida em que, subvertendo a arrumação da cronologia, termina por surpreender relações, correlações e interrelações suscitadas pelos artigos, quer seja entre a tradição plural e o presente, entre a modernidade e a pós-modernidade e, claro, entre a Poesia, a Literatura e outros sistemas culturais, do passado e do presente. O leitor, por isto, é livre para encetar o seu passeio pessoal pelos vários textos que ora se publicam, inventando então um sexto percurso de re/conhecimento e aprendizado.

Como nota final, registramos que com a publicação deste volume 13 da revista TextoPoético, encerramos nossa temporada de coordenação do GT Teoria do Texto Poético/ANPOLL e da respectiva edição da revista TextoPoético, trabalhos que se estenderam de julho de 2008 a julho de 2012. Com isto, queremos agradecer a confiança em nós depositada por todos os colegas do GT, bem como a inestimável colaboração de todos aqueles (autores de artigos e resenhas, poetas convidados, entrevistadores, pareceristas, equipe técnica e membros do corpo editorial) que conosco estiveram entre o vol.6 (I/2009) e o vol.13 (II/2012), que ora se publica, da inestimável revista TextoPoético.

Com os melhores cumprimentos,

Antônio Donizeti Pires

Solange Fiuza Cardoso Yokozawa

Araraquara/Goiânia, outubro de 2012. 